\title{
Correlations between fruit yield and sensory and nutritional quality of pumpkin (Cucurbita moschata Duch.)
}

\author{
Rita Mércia Estigarribia Borges", Maria Auxiliadora Coêlho de Lima, Natoniel Franklin de Melo \\ Embrapa Semiárido, BR 428, km 152, - ZIP Code 56302-970 - Petrolina, Pernambuco State - Brazil.
}

\section{*Corresponding author: rita.faustino@embrapa.br}

\begin{abstract}
Traits related to fruit yield and physical and chemical fruit quality are being evaluated by Embrapa pumpkin breeding program. Path and Pearson's correlation analysis are necessary to allow the knowledge of the relation between the variables of interest for this program. The objective of the present study was to determine the genetic correlations between yield- and sensorial and nutritional quality attributes-associated variables in pumpkin progenies to support the selection process. Twelve genotypes were evaluated for 10 yield-related traits, and 8 sensory and nutritional quality traits of fruit, including the commercial cultivar Jacarezinho. A path analysis considered the fruit weight (FrW) was as basic variable and the others as explanatory. The FrW had $98 \%$ of its total variation available in a function of the explanatory variables. The highest variations were observed in the fruit-shape related traits. In addition, the variables internal median cavity diameter (IDmed), equatorial pulp thickness (EPT), apical pulp thickness (APT), and smallest fruit diameter (Dsm) are indicated for a direct selection of progenies targeting a higher FrW. The correlation analysis highlighted that color-related variables have the possibility of indirect selection aiming to increase total carotenoid content (TCC) and $\beta$-carotene content ( $\beta$-car). The evaluated progenies showed notable soluble solids content (SSC), TCC and $\beta$-car contents compared to the commercial cultivar. Furthermore, the contribution of $\beta$-car to TCC is at least $50 \%$ higher in these progenies than in 'Jacarezinho' pumpkin.
\end{abstract}

Keywords: cucurbits; path analysis; plant breeding; quality attributes; total carotenoids.

Abbreviations: VAD_Vitamin A deficiency; FrW_fruit weight; FrL_fruit length; Dla_largest fruit diameter; Dsm_smallest fruit diameter; IDIg_longitudinal internal cavity diameter; IDmed_internal median cavity diameter; AST_apex skin thickness; EST_equatorial skin thickness; APT_apical pulp thickness; EPT_equatorial pulp thickness; L_luminosity, C_chroma; $H_{-}$hue angle; SSC_soluble solids content; TA_titratable acidity; TCC_total carotenoid content; $\beta$-car_ $\beta$-carotene content; HPLC_high performance liquid chromatography; Rat_ß $\beta$-carotene and total carotenoid content ratio; ANOVA_analysis of variance; CV_coefficient of variation; DC_determination coefficient; E_effect of the residual variable.

\section{Introduction}

Yield is a complex character that is greatly influenced by several associated traits, which are controlled by many genes and whose expression is strongly influenced by the environment (Mustafa et al., 2018). In plant breeding, sufficient genetic variation is a condition for the selection of agronomically desirable genotypes, especially of traits highly correlated with each other and with yield (Khan et al., 2017). Thus, in the selection process, it is important to knowledge about the relationships between characteristics of interest, which can be done by determining the correlations between phenotypic characters (Santos et al., 2018). Sultana et al. (2015) affirm that the path analysis for supporting the development of varieties allows determining the direct and indirect effects of physical characteristics of fruits with the yield.

Similarly, correlations between fruit quality traits based on sensory properties such as appearance, texture, flavor, and aroma, as well as nutritional value and functional properties
(Abbot, 1999) are considered in the selection process for achieving the excellence degree of the product. These information are important to meet the criteria of quality and consumer requirements.

Pumpkin (Cucurbita moschata Duch.) is one of the plants that meets healthy nutrition requirements (Hong et al., 2015) and has a sweet and mild taste appreciated by consumers (Zhou et al., 2014). It is one of the most consumed cucurbitaceae and is recognized as a source of total carotenoids, mainly of $\beta$-carotene (Mezzomo and Ferreira, 2016; Saini et al., 2015). These pigments with highest provitamin A activity, of which $\beta$-carotene is the most abundant, are found naturally in vegetables and are converted to vitamin A in the body.

In Brazil, mainly Northeast, vitamin A deficiency (VAD) is a serious public health problem of reproductive-age women and under five-year-old children $(29.4 \%$ and $12.3 \%$, respectively) (Miglioli et al., 2015). Clinical observations 
early in the $20^{\text {th }}$ century indicated the importance of vitamin A for innumerable bodily functions in humans. Besides, various ocular manifestations as night blindness and xerophthalmia (Janani et al., 2018) were associated with vitamin A deficiency and protein-energy malnutrition, usually associated with poor carotenoids, mainly $\beta$-carotene. The evaluation and development of productive pumpkin genotypes with high commercial quality and high $\beta$-carotene levels is understood as an effective strategy to prevent VAD. In Brazil, the Embrapa pumpkin breeding program is based on the variability in germplasm collected from the Northeast Brazilian region (Borges et al., 2019). Therefore, using this germplasm promote good chances of gains in the selection for genotypes with high commercial value and total carotenoid content and particularly high $\beta$-carotene levels. The breeding program developed progenies with commercial and nutritional traits of interest, which should be evaluated for the next selection phases.

The objective of the present study was to determine the genetic correlations between yield- and sensorial and nutritional quality attributes-associated variables in pumpkin progenies to support the selection process.

\section{Results}

\section{Analysis of variance (ANOVA) and Scott Knott's test}

The ANOVA indicated significant differences among the evaluated progenies $(P<0.01)$. The coefficient of variation (CV) ranged from 1.67 for variable (C) of pulp to 45.56 for Dsm (Table 2S).

In the grouping of means through the Scott Knott's test $(P<$ $0.05)$, the greatest variations for the mean values among genotypes were observed in the variables associated with fruit shape (Table 1). The FrW values varied from $2.52 \mathrm{~kg}$ in control (cultivar Jacarezinho) to $4.17 \mathrm{~kg}$ in progeny $C$. moschata 7.

The highest mean fruit length $(\mathrm{FrL})$ was found for progeny $C$. moschata 3 , distinguishing to the others (Table 1 ). In addition, the progenies $C$. moschata $1, C$. moschata 4 and $C$. moschata 8 formed a group with $\mathrm{FrL}$ values of $29 \mathrm{~cm}$, approximately. When comparing the means of FrL with those of largest fruit diameter (Dla), an inverse relationship between the two variables was observed, i.e., high $\mathrm{FrL}$ was related with low Dla (Table 1).

For Dsm, the genotypes C. moschata 7 and 'Jacarezinho' formed a group with value zero for this variable, showing the direct relation between the smallest fruit diameter and elongated shape (Table 1). With regard to the longitudinal internal cavity diameter (IDIg) variable, it is possible to highlight the progenies $C$. moschata $1, C$. moschata 3 and $C$. moschata 8 (Table 1). These progenies also formed a group with the lowest values for the IDmed (Table 1).

The apex skin thickness (AST) ranged from $2.63 \mathrm{~mm}$ in 'Jacarezinho' to $7.07 \mathrm{~mm}$ in the progeny C. moschata 5 (Table 1). The lowest value for equatorial skin thickness (EST) is $2.70 \mathrm{~mm}$. It was recorded for cultivar Jacarezinho (Table 1). A group with similar EST was formed with the progenies $C$. moschata $2, C$. moschata $3, C$. moschata 5 , and C. moschata 11.

The highest values for APT were observed for the progenies
C. moschata 1, C. moschata 3, C. moschata 4, and C. moschata 8 , which were characterized as genotypes with high FrL values (Table 1). For EPT variable, the highest mean values were found in C. moschata 7 and C. moschata 11 (Table 1).

Regarding the variables associated with pulp color, the highest value of luminosity (L) was found for 'Jacarezinho', while there were no significant differences among the evaluated progenies (Table 1). Opposite response was observed for variable $\mathrm{C}$, which all progenies were characterized by high intensity or purity of color compared to control (Table 1). In this study, differences of $15-20 \%$ in the hue angle $(\mathrm{H})$ color attribute corresponded to TCC up to four times higher in the progenies than in the control (Table 1). This result shows that the estimates of TCC generated with the hue angle are only valid for contrasting genotypes. Analysis of variables related to flavor indicated that SSC above 12 oBrix were observed, except for progeny $C$. moschata 10 and control (Table 1). However, greater differences among progenies were observed to titratable acidity (TA), forming two groups (Table 1 ). In the first one, $50 \%$ of the genotypes presented values ranging from 0.20 to $0.25 \%$, including control. The values of the others genotypes ranged from 0.27 to $0.29 \%$.

The close association between TCC and $\beta$-car variables resulted in formation of groups containing the same genotypes (Table 1 ). The values of TCC and $\beta$-car that observed for $C$. moschata 6 were approximately 2.5 and 3.4 times, respectively, higher than the contents of the commercial cultivar. For the other progenies, TCC and $\beta$-car values reached 437 and $340 \mu \mathrm{g} \cdot \mathrm{g}^{-1}$, respectively. In addition, the $\beta$-car content in 'Jacarezinho' reached only $53 \%$ of TCC, named $\beta$-car and TCC ratio, while it reached $75-80 \%$ in the progenies generated by Embrapa pumpkin breeding program.

\section{Path analysis for the variables associated with yield}

All variables were subjected to correlation analysis, and the correlations between yield variables subjected to path analysis (Table 2). The coefficient of determination for path analysis was 0.98 and the coefficient of the residual variable (E) 0.12 . The determination of coefficient (DC) indicated that the variables explained $98 \%$ of the variation that occurred in the basic FrW variable (Table 2).

Complementarily, a path diagram was prepared to show the correlations between the explanatory variables using bidirectional arrows, as well as the direct effects of variables on basic variable, indicated by bold values and arrows in a unidirectional way and E (Figure 1). For the positive or negative correlations of greater interest in the explanatory variables $(0.80 \leq r \leq 0.99)$, highly significant coefficients were observed between FrL and APT (0.97); Dla and IDmed (0.96); FrL and IDIg (0.93); FrL and Dsm (0.84); AST and EST (0.84); IDIg and APT (0.81), and APT and EPT (-0.86).

\section{Pearson's correlation for the sensorial and nutritional quality attributes}

The correlations between the variables associated with fruit pulp quality are shown in Table 3. For the positive or 
Table 1. Mean of 18 fruit traits associated in pumpkin progenies and cultivar Jacarezinho.

\begin{tabular}{|c|c|c|c|c|c|c|c|c|c|}
\hline Treatments & FrW & $\mathrm{FrL}$ & Dla & Dsm & IDIg & IDmed & AST & EST & APT \\
\hline C. moschata 1 & $2.63 \mathrm{c}$ & $28.98 b$ & $14.87 \mathrm{e}$ & $9.04 \mathrm{a}$ & $15.78 \mathrm{a}$ & $10.39 \mathrm{~d}$ & $5.58 \mathrm{~b}$ & $5.16 \mathrm{~b}$ & $63.68 \mathrm{a}$ \\
\hline C. moschata 2 & $3.91 \mathrm{a}$ & $19.59 \mathrm{c}$ & $21.49 \mathrm{~b}$ & $3.95 b$ & $12.57 \mathrm{~b}$ & $14.78 \mathrm{a}$ & $5.87 \mathrm{~b}$ & $5.76 \mathrm{a}$ & $31.02 \mathrm{~b}$ \\
\hline C. moschata 3 & $3.36 \mathrm{~b}$ & $32.21 \mathrm{a}$ & $16.47 d$ & $10.32 \mathrm{a}$ & $16.03 \mathrm{a}$ & $11.67 \mathrm{~d}$ & $6.02 \mathrm{~b}$ & $5.43 \mathrm{a}$ & $69.09 \mathrm{a}$ \\
\hline C. moschata 4 & $2.67 c$ & $29.27 b$ & $16.53 \mathrm{~d}$ & $8.53 \mathrm{a}$ & $12.87 \mathrm{~b}$ & $12.67 \mathrm{c}$ & $6.60 \mathrm{a}$ & $4.44 \mathrm{c}$ & $75.47 a$ \\
\hline C. moschata 5 & $2.31 \mathrm{c}$ & $19.01 \mathrm{c}$ & $18.03 \mathrm{~d}$ & $8.11 \mathrm{a}$ & $10.40 \mathrm{c}$ & $13.48 \mathrm{~b}$ & $7.07 \mathrm{a}$ & $6.15 \mathrm{a}$ & $38.72 b$ \\
\hline C. moschata 6 & $2.89 \mathrm{c}$ & $19.40 \mathrm{c}$ & $17.27 \mathrm{~d}$ & $7.4 \mathrm{a}$ & $12.40 \mathrm{~b}$ & $11.53 \mathrm{~d}$ & $5.89 \mathrm{~b}$ & $4.92 \mathrm{~b}$ & $32.2 b$ \\
\hline C. moschata 7 & $4.17 \mathrm{a}$ & $17.23 \mathrm{c}$ & $23.17 \mathrm{a}$ & $0.0 \mathrm{~b}$ & $10.43 \mathrm{c}$ & $15.97 \mathrm{a}$ & $4.06 \mathrm{c}$ & $4.29 c$ & $28.71 b$ \\
\hline C. moschata 8 & $2.86 \mathrm{c}$ & 29.62 b & $15.17 \mathrm{e}$ & $9.51 \mathrm{a}$ & $15.01 \mathrm{a}$ & $11.24 \mathrm{~d}$ & $6.56 \mathrm{a}$ & $5.11 b$ & $67.62 \mathrm{a}$ \\
\hline C. moschata 9 & $3.08 \mathrm{c}$ & $16.36 \mathrm{c}$ & $19.80 \mathrm{c}$ & $2.8 \mathrm{~b}$ & $10.44 \mathrm{c}$ & $13.37 \mathrm{~b}$ & $4.60 \mathrm{c}$ & $4.03 c$ & $25.89 \mathrm{~b}$ \\
\hline C. moschata 10 & $2.72 \mathrm{c}$ & $13.68 d$ & $20.91 b$ & $2.25 \mathrm{~b}$ & $7.29 \mathrm{~d}$ & $14.87 \mathrm{a}$ & $5.74 \mathrm{~b}$ & $4.71 \mathrm{~b}$ & $24.71 b$ \\
\hline C. moschata 11 & $4.01 \mathrm{a}$ & $17.63 \mathrm{c}$ & $21.77 \mathrm{~b}$ & $9.14 \mathrm{a}$ & $9.98 \mathrm{c}$ & $15.08 \mathrm{a}$ & $5.79 \mathrm{~b}$ & $5.49 \mathrm{a}$ & $31.20 \mathrm{~b}$ \\
\hline Jacarezinho & $2.52 \mathrm{c}$ & $12.04 \mathrm{~d}$ & $19.11 \mathrm{c}$ & $0.0 \mathrm{~b}$ & $6.74 \mathrm{~d}$ & $12.89 \mathrm{c}$ & $2.63 \mathrm{~d}$ & $2.70 \mathrm{~d}$ & $23.35 b$ \\
\hline Treatments & EPT & $\mathrm{L}$ & $\mathrm{C}$ & $\mathrm{H}$ & $\mathrm{SSC}$ & TA & TCC & $\beta$-car & Rat \\
\hline C. moschata 1 & $17.44 \mathrm{~d}$ & $63.13 b$ & $70.44 \mathrm{a}$ & $58.49 \mathrm{~b}$ & $13.85 \mathrm{a}$ & $0.29 \mathrm{a}$ & $384.55 \mathrm{a}$ & $297.85 \mathrm{a}$ & $77.02 \mathrm{a}$ \\
\hline C. moschata 2 & $26.05 b$ & $62.44 \mathrm{~b}$ & $70.41 \mathrm{a}$ & $57.92 b$ & $12.23 \mathrm{a}$ & $0.22 \mathrm{~b}$ & $380.56 \mathrm{a}$ & $287.21 \mathrm{a}$ & $75.64 \mathrm{a}$ \\
\hline C. moschata 3 & $21.36 \mathrm{c}$ & $60.81 b$ & $69.23 \mathrm{a}$ & $58.61 b$ & $13.90 \mathrm{a}$ & $0.28 a$ & $350.88 \mathrm{a}$ & $280.56 \mathrm{a}$ & $75.00 \mathrm{a}$ \\
\hline C. moschata 4 & $15.72 \mathrm{~d}$ & $61.62 \mathrm{~b}$ & $67.14 \mathrm{~b}$ & $57.11 b$ & $14.11 \mathrm{a}$ & $0.24 \mathrm{~b}$ & $428.90 \mathrm{a}$ & $341.73 \mathrm{a}$ & 79.35 a \\
\hline C. moschata 5 & $16.61 \mathrm{~d}$ & $63.43 b$ & $69.83 \mathrm{a}$ & $59.34 \mathrm{~b}$ & $14.18 \mathrm{a}$ & $0.27 \mathrm{a}$ & $382.49 \mathrm{a}$ & $304.75 \mathrm{a}$ & 79.45 a \\
\hline C. moschata 6 & $26.88 b$ & $63.50 \mathrm{~b}$ & $68.64 \mathrm{a}$ & $59.69 \mathrm{~b}$ & $12.60 \mathrm{a}$ & $0.24 \mathrm{~b}$ & $260.08 \mathrm{~b}$ & $200.23 \mathrm{~b}$ & $76.11 \mathrm{a}$ \\
\hline C. moschata 7 & $32.51 \mathrm{a}$ & $61.48 \mathrm{~b}$ & $69.55 \mathrm{a}$ & $56.46 \mathrm{~b}$ & $13.18 \mathrm{a}$ & $0.25 b$ & $414.50 \mathrm{a}$ & $325.04 \mathrm{a}$ & $78.68 \mathrm{a}$ \\
\hline C. moschata 8 & $17.02 \mathrm{~d}$ & $62.67 \mathrm{~b}$ & $68.65 \mathrm{a}$ & $58.80 \mathrm{~b}$ & $13.69 \mathrm{a}$ & $0.28 a$ & 399.74 a & $312.35 \mathrm{a}$ & $77.53 \mathrm{a}$ \\
\hline C. moschata 9 & $28.38 \mathrm{~b}$ & $63.50 \mathrm{~b}$ & $69.81 \mathrm{a}$ & $58.21 b$ & $12.83 \mathrm{a}$ & $0.28 a$ & $435.53 \mathrm{a}$ & 341.07 a & 77.99 a \\
\hline C. moschata 10 & $27.94 \mathrm{~b}$ & $62.26 \mathrm{~b}$ & $69.31 \mathrm{a}$ & $57.90 \mathrm{~b}$ & $11.58 \mathrm{~b}$ & $0.24 \mathrm{~b}$ & $437.49 \mathrm{a}$ & $339.75 \mathrm{a}$ & $77.22 \mathrm{a}$ \\
\hline C. moschata 11 & $31.22 \mathrm{a}$ & $62.51 \mathrm{~b}$ & $70.29 a$ & $58.11 b$ & $13.57 \mathrm{a}$ & $0.27 a$ & $410.10 \mathrm{a}$ & $327.89 a$ & $78.37 \mathrm{a}$ \\
\hline Jacarezinho & $29.14 b$ & $70.04 \mathrm{a}$ & $65.04 \mathrm{c}$ & $66.65 \mathrm{a}$ & $10.07 \mathrm{~b}$ & $0.20 \mathrm{~b}$ & $106.50 \mathrm{c}$ & $58.99 c$ & $53.16 \mathrm{~b}$ \\
\hline
\end{tabular}

Means followed by the same letter do not differ statistically from each other by the Scott-Knott test at $5 \%$ probability. FrW = fruit weight $(\mathrm{kg}) ; \mathrm{FrL}=$ length $(\mathrm{cm}) ;$ Dla $=$ largest diameter $(\mathrm{cm}) ;$ Dsm $=\mathrm{smallest}$ diameter $(\mathrm{cm})$; $\mathrm{IDIg}=$ longitudinal diameter of the internal cavity $(\mathrm{cm}) ; \mathrm{IDmed}=$ median diameter of the internal cavity $(\mathrm{cm}) ; A S T=$ apical skin thickness $(\mathrm{mm}) ; \mathrm{EST}=$ equatorial skin thickness $(\mathrm{mm}) ; \mathrm{APT}=$ apical pulp thickness $(\mathrm{mm}) ; \mathrm{EPT}=$ equatorial pulp thickness $(\mathrm{mm}) ; \mathrm{L}=$ luminosity pulp color; $\mathrm{C}=$ Chroma; $\mathrm{H}=$ hue angle; $\mathrm{SSC}=$ soluble solids content $\left({ }^{0} \mathrm{Brix}\right) ; \mathrm{TA}=$ titratable acidity $\left(\%\right.$ citric acid); $\mathrm{TCC}=$ total carotenoid content $\left(\mu \mathrm{g} . \mathrm{g}^{-1}\right) ; \beta$-car $=\beta$-carotene content $\left(\mu \mathrm{g} \cdot \mathrm{g}^{-1}\right)$; and Rat $=$ ratio between $\beta$-carotene and total carotenoid content $(\%)$.

Table 2. Direct, indirect and total effects of eight fruit variables on the variable fruit weight in pumpkin.

\begin{tabular}{|c|c|c|c|c|c|c|c|c|c|c|c|}
\hline Trait & Effect & Via & FrW & Trait & Effect & Via & FrW & Trait & Effect & Via & FrW \\
\hline \multirow[t]{9}{*}{ FrL } & Direct & & -0.92 & Dla & Direct & & 0.04 & Dsm & Direct & & 0.40 \\
\hline & Indirect & Dla & -0.03 & & Indirect & $\mathrm{FrL}$ & 0.69 & & Indirect & FrL & -0.72 \\
\hline & & Dsm & 0.31 & & & Dsm & -0.27 & & & Dla & -0.03 \\
\hline & & IDIg & 1.29 & & & IDIg & -0.93 & & & IDIg & 1.02 \\
\hline & & IDmed & -0.66 & & & IDmed & 0.95 & & & IDmed & -0.59 \\
\hline & & AST & -0.14 & & & AST & 0.10 & & & AST & -0.19 \\
\hline & & EST & -0.03 & & & EST & 0.01 & & & EST & -0.05 \\
\hline & & APT & 0.55 & & & APT & -0.45 & & & APT & 0.43 \\
\hline & & EPT & -0.46 & & & EPT & 0.51 & & & EPT & -0.42 \\
\hline Total (r) & & & -0.09 & Total $(r)$ & & & 0,66 & Total $(r)$ & & & $-0,16$ \\
\hline Trait & Effect & Via & FrW & Trait & Effect & Via & FrW & Trait & Effect & Via & FrW \\
\hline \multirow{9}{*}{ IDlg } & Direct & & 1.39 & IDmed & Direct & & 0.99 & AST & $\begin{array}{l}\text { Direct } \\
\end{array}$ & & -0.25 \\
\hline & Indirect & FrL & -0.85 & & Indirect & FrL & 0.61 & & Indirect & FrL & -0.52 \\
\hline & & Dla & -0.03 & & & Dla & 0.04 & & & Dla & -0.02 \\
\hline & & Dsm & 0.29 & & & Dsm & -0.23 & & & Dsm & 0.31 \\
\hline & & IDmed & -0.65 & & & IDlg & -0.91 & & & IDlg & 0.73 \\
\hline & & AST & -0.13 & & & AST & 0.05 & & & IDmed & -0.23 \\
\hline & & EST & -0.04 & & & EST & 0.00 & & & EST & -0.07 \\
\hline & & APT & 0.46 & & & APT & -0.38 & & & APT & 0.31 \\
\hline & & EPT & -0.38 & & & EPT & 0.41 & & & EPT & -0.41 \\
\hline Total (r) & & & 0.05 & Total $(\mathrm{r})$ & & & 0.59 & Total (r) & & & -0.15 \\
\hline Trait & Effect & Via & FrW & Trait & Effect & Via & FrW & Trait & Effect & Via & FrW \\
\hline \multirow[t]{9}{*}{ EST } & Direct & & -0.08 & APT & Direct & & 0.57 & EPT & Direct & & 0.61 \\
\hline & Indirect & FrL & -0.37 & & Indirect & FrL & -0.89 & & Indirect & FrL & 0.70 \\
\hline & & Dla & -0.01 & & & Dla & -0.03 & & & Dla & 0.04 \\
\hline & & Dsm & 0.26 & & & Dsm & 0.30 & & & Dsm & -0.27 \\
\hline & & IDIg & 0.69 & & & IDIg & 1.13 & & & IDIg & -0.87 \\
\hline & & IDmed & -0.02 & & & IDmed & -0.65 & & & IDmed & 0.66 \\
\hline & & AST & -0.21 & & & AST & -0.13 & & & AST & 0.17 \\
\hline & & APT & 0.16 & & & EST & -0.02 & & & EST & 0.03 \\
\hline & & EPT & -0.24 & & & EPT & -0.50 & & & APT & -0.47 \\
\hline Total (r) & & & 0.17 & Total (r) & & & -0.24 & Total (r) & & & 0.60 \\
\hline$D C=0.98$ & & & & & & & & & & & \\
\hline
\end{tabular}

$\mathrm{FrW}=$ fruit weight; FrL = length; Dla = largest diameter; Dsm = smallest diameter; IDlg = longitudinal diameter of the internal cavity; IDmed = median diameter of the internal cavity, AST = apical skin thickness; EST = equatorial skin thickness; APT = apical pulp thickness, and EPT = equatorial pulp thickness. $r=$ Pearson correlation coefficient; $D C=$ Determination coefficient and and E $=$ Effect of the residual variable. 


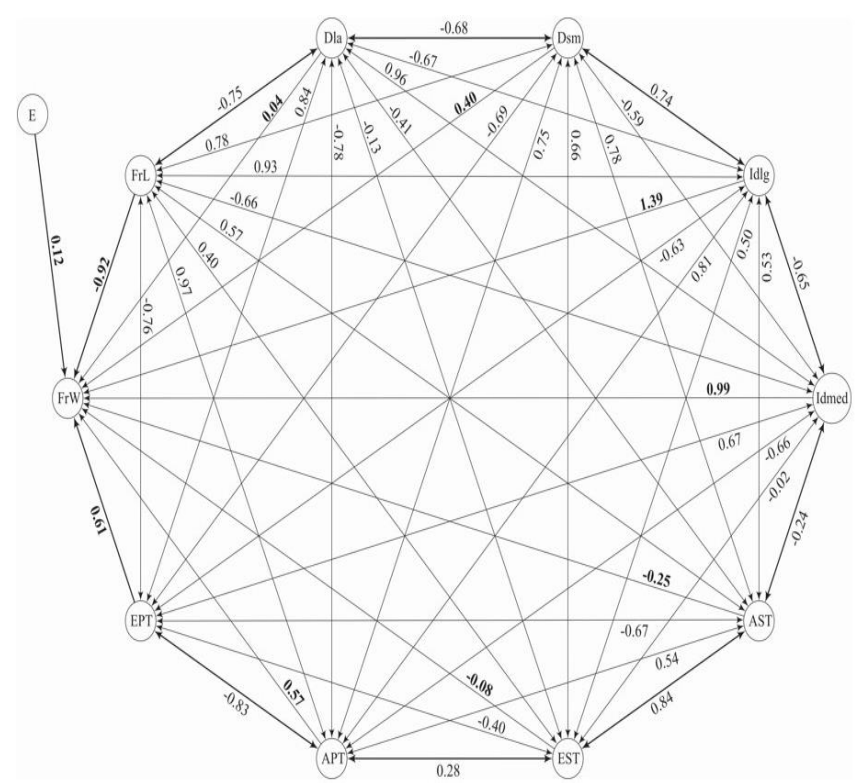

Fig 1. Path diagram on correlations between explanatory variables and their direct effects on the basic variable in pumpkin. Unidirectional arrows as well as values in bold, indicate the direct effects of the explanatory variables on the basic variable and the effect of the residual variable, respectively. Bidirectional arrows indicate the correlations between the explanatory variables.

Table 3. Pearson's correlation coefficients for sensorial and nutritional quality attributes in fruits of pumpkin progenies (C. moschata).

\begin{tabular}{|c|c|c|c|c|c|c|c|}
\hline & $C$ & $\mathrm{H}$ & SS & TA & TCar & $\beta$-car & Rat \\
\hline$L$ & $-0.68^{*}$ & $0.95 * *$ & $-0.72^{* *}$ & -0.40 & $-0.84^{* *}$ & $-0.85^{* *}$ & $-0.90^{* *}$ \\
\hline C & & $-0.73^{* *}$ & 0.43 & 0.17 & $0.70^{* *}$ & $0.70 * *$ & $0.76^{* *}$ \\
\hline $\mathrm{H}$ & & & -0.56 & -0.15 & $-0.92^{* *}$ & $-0.93 * *$ & $-0.94 * *$ \\
\hline SS & & & & $0.73^{* *}$ & 0.49 & 0.54 & $0.62^{*}$ \\
\hline TA & & & & & 0.09 & 0.12 & 0.12 \\
\hline TCar & & & & & & $0.99 * *$ & $0.89 * *$ \\
\hline$\beta$-car & & & & & & & $0.91^{* *}$ \\
\hline
\end{tabular}

** and * indicate significant correlations at 1 and $5 \%$ probability, respectively, by the $\mathrm{t}$-test. $\mathrm{L}=$ luminosity pulp color; $\mathrm{C}=$ chroma; $\mathrm{H}=$ hue angle; SSC $=$ soluble solids content; TA $=$ titratable acidity; TCC = total carotenoid content; $\beta$-car $=\beta$-carotene content, and Rat $=$ ratio between $\beta$-carotene and total $(\%)$.

negative correlations of greater interest in this study $(0.80 \leq$ $r \leq 0.99)$, highly significant coefficients were observed between $\mathrm{C}$ and $\mathrm{H} ; \mathrm{C}$ and TCC; $\mathrm{C}$ and $\beta$-car; $\mathrm{C}$ and $\beta$-car and Rat; $\mathrm{H}$ and TCC; $\mathrm{H}$ and $\beta$-car; $\mathrm{H}$ and Rat; TCC and $\beta$-car; TCC and Rat, and $\beta$-car and Rat.

\section{Discussion}

The results associated to ANOVA indicate existence of variability for the evaluated characters. In cucurbits, assessing heterogeneity and its magnitude in the genotypes through analysis of variance is highly relevant to ensure gains in the selection process (Ndukauba, et al., 2015). Heterogeneity is indicated by the coefficient of variation, and higher values indicate greater variability (Cyril et al., 2014; Singh et al., 2017). Studies focused on pumpkin FrW reported different results according to the evaluated genotypes. Du et al. (2011) measured a mean FrW of $2.9 \mathrm{~kg}$ in a diversity study of $C$. moschata lines, while Soltani et al. (2016) recorded mean FrW values of $5.8 \mathrm{~kg}$ in $C$. moschata when estimating the genetic diversity in accessions of different species of the genus Cucurbita. Fruit weight is one of the traits of key interest in the pumpkin breeding program, targeting the development of lines with a FrW of approximately $3 \mathrm{~kg}$. Therefore, the mean FrW of the progenies evaluated in this study are close to the desired. The ratio of fruit length to diameter defines its shape. According to Chitarra and Chitarra (2005), values lower than 1 in this ratio indicate globular, ellipsoidal and spherical shapes. Therefore, when the length is greater than the diameter (ratio $>1$ ) the fruit shape is elongated. For the evaluated progenies and control 'Jacarezinho', a comparison of the mean Dla with mean FrL values, shows the similarity with the described fruit shapes of the mother progenies described in Table 1S, indicating the possibility of selection among the progenies for a cultivar with either globular, piriform or flattened fruit shape. Fruit shape influences the measures associated with its internal cavity, i.e., fruits with a larger cavity produce a larger number of seeds, resulting in a lower FrW. Nerson et al. (2000) reported the association between increased fruit size and fruit destination for in natura consumption or for seed production, in Cucurbita. The authors emphasized the need of increasing the fruit cavity when the objective is the production of seeds. In the progenies evaluated here for IDIg and IDmed, selection should target a reduction of the internal cavity. Traits such as skin and pulp thickness of pumpkin are studied, since the yield of fruits with a thicker pulp is greater (Du et al., 2011), which is a relevant factor for the commercialization and processing of several fruits (Blank et al., 2013). In this study, the progenies with highest mean values of APT were those one with high FrL. The appearance and acceptability of fruits by consumers are directly related to their color (Zhao et al., 2015), which is a complex variable defined by a number of elements. For example, luminosity is one of these factors and represents the surface brightness. It can vary from 0 (black) to 100 (white) 
(Albertini et al., 2012). For pumpkin, the orange pulp color is an important quality component. According to Sasaki et al. (2014), the hue angle or color angle is the variable that best defines this trait. In this case, values below 750 and above 30 ㅇ represent the orange color, where lower values define darker color tones. In this study, the evaluation of the $\mathrm{H}$ resulted in groups of progenies with no significant differences between each other, but differing significantly from the control. When this finding was compared with the results obtained for the variables TCC, $\beta$-car and Rat, the groupings for the three variables indicated high levels of these compounds in all evaluated progenies.

According to Adubofuor et al. (2016), TA is important for a balanced flavor, and a low pH maintains the pulp color more stable, inhibiting microbial deterioration. The same authors stated that the variables SSC and TA are relevant because they indicate the stage of fruit maturation and the definition of the ideal SSC and TA levels that can be used as an indicator of harvest maturity (Adubofuor et al., 2016). However, the mean SSC values of the progenies were close to the limit of 11 to 13으ix, described by Loy (2004) as ideal for post-harvested pumpkin. Both progenies and the control Jacarezinho had market-grade SSC values. For TA, the values of the progenies were as expected for this fruit, with uniformity among the progenies for this trait.

The information generated by correlation analysis can be used to increase breeding efficiency and reduce plant populations during the selection process (Soltani et al., 2016). For pumpkin, few studies used correlation path analysis. Khan et al. (2017) identified the fruit weight as one of the traits that allows the selection of productive genotypes of snake gourd (Trichosamthes cucumerina, var. anguina). According to Naik et al. (2015), path analysis allows an understanding of the direct or indirect contribution of each variable to the dependent and yield-related variables. These authors also emphasized that for breeding, it is important to identify traits strongly correlated with the basic variable and with a major direct effect in favour of selection. This ensures that the correlated response by indirect selection is efficient.

According to Souza (2013), the interpretation of the results of the path analysis showed that when the direct effect of an explanatory variable is smaller than the modulus of the residual effect, but the correlation coefficient ( $r$ ) or total effect is greater than the residual variable. This variable influences the main variable only indirectly. Therefore, it is only important together with the other explanatory variables, as was the case for variable Dla.

According to the same author, if the direct effect is greater than the residual one, the effect of the variable would be direct. The variables with the greatest influence, with direct effect estimates in this condition were IDIg (1.39), IDmed (0.99), EPT (0.61), APT (0.57), and Dsm (0.40).

Although variable IDlg had the greatest direct effect (11.58 times greater than the effect of the residual variable), the positive correlation with FrW is very low (0.05). It was also observed that IDIg influences the variable FrL indirectly, indicating that long fruits have lower FrW. This result allows the conclusion that the variables with direct effect on FrW, IDmed, EPT, APT, and Dsm can be used with greater efficiency in direct selection for higher fruit weight.

Most of the correlations between the explanatory variables are positive (Figure 1). Therefore, according to the coefficients of correlation between FrL and APT; Dla and IDmed; FrL and IDIg; FrL and Dsm; AST and EST, and IDIg and APT, the selection of genotypes can be made based on the variable of greatest interest. The highly significant and negative correlation observed between the APT and EPT variables indicating that the indirect selection can be made according to the fruit shape desired, hence fruits with globular shape will have higher EPT and piriform shape fruits will have higher APT. The correlation between variables related to pulp color attributes and pigments showed that fruits with higher $\mathrm{C}$ and $\mathrm{H}$ (positive correlation between these variables) were characterized by lower TCC and $\beta$-car, as well as Rat.

The significance of the $\mathrm{H}$ for the estimation of high TCC and $\beta$ car levels in contrasting genotypes is corroborated here by the inverse correlation between the variables $\mathrm{H}$ and TCC, $\beta$-car and Rat. Martínez-Valdivieso et al. (2015) also reported the inverse association between variables that confer pulp color and total carotenoids content as lutein in a study for the physical and chemical characterization of 22 summer squash genotypes. In this case, it is possible to determine that the correlation between variables associated with the color and the contents of this carotenoid would ensure indirect selection in the evaluated genotypes. Significant and negative correlations were also observed by Itle and Kabelka (2009) for $\mathrm{C}$ and $\mathrm{H}$ and for variable $\beta$-car in squashes of $C$. moschata and $C$. pepo species. The authors concluded that high correlation values also allow for indirect selection for higher $\beta$-car levels.

\section{Material and Methods}

\section{Plant materials}

The pumpkin species used in this experiment was $C$. moschata Duch. Twelve pumpkin genotypes were evaluated, of which 11 were progenies from accessions of the living Cucurbita genebank of Embrapa, selected for agronomic and fruit quality, including total carotenoid and $\beta$-carotene. The commercial cultivar Jacarezinho was used as control (Table $2 \mathrm{~S})$. Of these 11 progenies, eight are second-cycle $\left(\mathrm{S}_{2}\right)$ selfed progenies from the accessions BGC545 (C. Moschata $1, C$. moschata 3, C. moschata 4, C. moschata 5, C. moschata 6, C. moschata 8, C. moschata 9 , and C. Moschata 10), one from accession BGC567 (C. moschata 2), one from BGC569 (C. moschata 7), and one from a cycle of recurrent bulk selection of accessions named BGC432, BGC567, BGC498, BGC504, BGC545, and BGC620 (C. moschata 11).

\section{Chemicals and reagents used in the analysis}

To determine the total $\mathrm{TA}$, we used $0.1 \mathrm{~N} \mathrm{NaOH}$ and phenolphthalein as indicator (IAL, 1985). The following solutions and reagents were used for total carotenoid extraction: acetone (Dinâmica Contemporânea, Diadema São Paulo (SP), Brazil); petroleum ether (Vetec, Duque de Caxias - SP, Brazil); anhydrous sodium sulfate (Dinâmica, Diadema - SP, Brazil), and sodium chloride (Cinética, Jandira - SP, Brazil). To determine the total carotenoid and $\beta$ carotene pigments, we used acetone, methyl terc-butyl ether (MTBE), as well as the $\beta$-carotene standard (minimum purity $\geq 95 \%$ ) (Sigma, Fairfield, Connecticut, USA). 


\section{Experimental site}

The experiment was carried out in Bebedouro Experimental Field/Embrapa Semiárido, located in Petrolina-Pernambuco (09-09'S, 4022'W; $365.5 \mathrm{~m}$ a.s.I.), from February to July 2015. During the experiment, the climate was defined by a mean temperature of $26.2^{\circ} \mathrm{C}$, minimum of $19.0^{\circ} \mathrm{C}$ and maximum of $32.5^{\circ} \mathrm{C}$, mean relative air humidity of $64.8 \%$, and cumulative rainfall of $38.2 \mathrm{~mm}$ in the study period (Embrapa, 2015).

The harvested fruits were analyzed at the Laboratory of Post-Harvest Physiology of Embrapa Semiárido.

\section{Field procedures}

The seeds were sown in polystyrene trays filled with commercial substrate, on February 16, 2015. The seedlings were planted in rows, with 21 plants each 13 days after seed germination, on March 2, 2015, at a spacing of $4 \mathrm{~m} \times 2.5 \mathrm{~m}$. The soil was prepared by plowing and disking. Fertilization was applied according to the recommendations, based on soil analysis (Cavalcanti, 2008). The cultivation area was maintained free of invasive plants, by hand weeding. Irrigation was applied by a drip system three times a week, at water levels of around $10 \mathrm{~mm}$, defined based on class-A pan evaporation. Phytosanitary measures for prevention and control of the silverleaf whitefly (Bemisia argentifolii) and powdery mildew (Podosphaera xanthii), common on crops in the region, were applied. Harvest occurred on July 2015, by hand, selecting the best fruit of each plant, by a visual evaluation of healthy fruits, without damages on the skin and preserving the fruit traits of the progeny grown from a seed of the mother plant.

\section{Studied variables}

The correlation analysis were based on the yield-related traits: FrW, in $\mathrm{kg}$, by weighing each fruit separately on a semi-analytical balance with a weighing capacity of up to 30 $\mathrm{kg}$ and variation up to $1 \%$ (Mettler-Toledo, model PBK989AB30, Barueri, SP, Brazil); FrL, Dla, Dsm, IDlg and IDmed, determined with a digital caliper (LeroyMerlin, Nœux-lesMines, France), in cm; AST, EST, APT and EPT, also measured with a digital caliper, but expressed in $\mathrm{mm}$.

For the correlation analysis of sensory and nutritional quality traits, the following traits were evaluated: pulp color, determined with a Konica Minolta CR400 Chroma Meter (Ramsey, NJ, USA). The properties L, C and H; SSC, expressed in ${ }^{\circ}$ Brix were measured in an Atago-PAL-1 digital refractometer Atago, PAL-1 (Bellevue, WA, USA), with automatic temperature compensation (AOAC, 1998); TA, in $\mathrm{mg}$ of citric acid $100 \mathrm{~mL}^{-1}$ by titration with $0.1 \mathrm{~N} \mathrm{NaOH}$ solution, using phenolphthalein as indicator (IAL, 1985) and the Bureta Digital $50 \mathrm{ml}$ Digitrate Jencons-Alpax (Diadema, SP, Brazil); TCC (in $\mu \mathrm{g} \cdot \mathrm{g}^{-1}$ ); $\beta$-car (in $\mu \mathrm{g} \cdot \mathrm{g}^{-1}$ ). These compounds were extracted by the method recommended by RodriguezAmaya and Kimura (2004) from $5 \mathrm{~g}$ of each fruit. The quantities were determined by high performance liquid chromatography (HPLC) using a Waters $^{\circledR}$ Alliance 2695 separation module coupled to a Waters ${ }^{\circledR} 2998$ Diode Array Detector (DAD) (Milford, Massachusetts, MA, USA), at 450 $\mathrm{nm}$. The extracts were run on a $4.6 \mathrm{~mm} \times 150 \mathrm{~mm} \mathrm{C}-30$
Carotenoid column (YMC/Waters Inc., Wilmington, NC), with a gradient program of: $0 \mathrm{~min}, 80 \%$ Methanol $+20 \%$ Terc Butyl Methyl Ether; 0.5 min, 75\% Methanol + 25\% Terc Butyl Methyl Ether; 15 min, 15\% Methanol $+85 \%$ Terc Butyl Methyl Ether; 15.05 min, 10\% Methanol + 90\% Terc Butyl Methyl Ether; 16.5 min, 10\% Methanol + 90\% Terc Butyl Methyl Ether; 16.55 min, 80\% Methanol $+20 \%$ Terc Butyl Methyl Ether; and 22 min, 80\% Methanol + 20\% Terc Butyl Methyl Ether, at a flow rate of $0.8 \mathrm{ml} \mathrm{min}^{-1}$ and oven temperature of $33^{\circ} \mathrm{C}$. In addition, the Rat was determined in percentage.

\section{Experimental design and statistical analysis}

The experiment was arranged in a randomized block design with four replications and seven plants per plot. The data distribution was tested by the Lilliefors' test (Ghasemi and Zahediasl, 2012). Due to not meeting the ANOVA assumptions, the variables SSC; TCC and $\beta$-car were transformed by the $\sqrt{x}$ function, while TA was transformed by the $\log x$ function. Thereafter, ANOVA was performed. Data were subjected to analysis of variance and grouping of means by the Scott-Knott test $(P<0.05)$.

Path analysis was performed considering FrW as basic variable and the others as explanatory. After, the path diagram with the direct effects in relation to the basic variable and the partial correlations between for the explanatory variables evaluated was obtained (Figure 1).

Finally, a correlation study was performed for the set of sensory and nutritional variables by Pearson's correlation coefficient. All statistical analyses were performed with software GENES (Cruz, 2013).

\section{Conclusion}

The highest variations were observed in the fruit-shape related traits, which is promising for selection among progenies for cultivars with elongated, globular or flattened fruit shape. The variables IDmed, EPT, APT, and Dsm are indicated for a direct selection of progenies targeting a higher FrW. The correlations between the color-related variables and those that quantify TCC and $\beta$-car indicate the possibility of indirect selection for contrasting genotypes in the pumpkin breeding program aiming to increase these compounds contents. The evaluated progenies showed notable SSC, TCC and $\beta$-car contents compared to the commercial cultivar. In addition, the contribution of $\beta$-car to TCC is at least $50 \%$ higher in these progenies than in 'Jacarezinho' pumpkin.

\section{Acknowledgements}

The authors are grateful for the financial support given by Embrapa and the HarvestPlus Program. This article is a requirement for the $D$. Sc. title by RMEB at the UEFS, Plant Genetic Resources Postgraduate Program - Feira de Santana, Bahia State - Brazil.

\section{References}

Abbot JA (1999) Quality measurement of fruits and vegetables. Postharvest Biol Technol. 15(3): 207-225. 
Adubofuor J, Amoah I, Agyekum PB (2016) Physicochemical properties of pumpkin fruit pulp and sensory evaluation of pumpkin-pineapple juice blends. Afr. J of Food Sci. and Tech. 4(4): 89-96.

Albertini S, Spoto MHF, Sarmento SBS (2012) Efeito de revestimentos comestíveis na conservação de mamões minimamente processados. Braz J Food Technol. 15(2): 125133.

AOAC- Association of Official Analytical Chemists (1998) Official Method of Analysis. 15th edn. AOAC, Washington.

Blank AF, Silva TB, Matos ML, Carvalho Filho JLS, Silva-Mann R (2013) Parâmetros genotípicos, fenotípicos e ambientais para caracteres morfológicos e agronômicos em abóbora. Hortic Bras. 31(1): 106-111.

Borges RME, Lima MAC de, Lima Neto, I da S, Melo NF de (2019) Prediction of genetic and selection parameters in pumpkin (Cucurbita moschata Duch.) progenies for morphoagronomic characteristics and pulp quality. Aust J Crop Sci. 13(2):199207.

Cavalcanti FJ de A (2008) Recomendações de adubação para o Estado de Pernambuco. 3rd edn. IPA, Recife.

Chitarra MIF, Chitarra AB (2005) Pós-colheita de frutas e hortaliças: fisiologia e manuseio. 2nd edn. Ufla, Lavras.

Cruz CD (2013) GENES. A software package for analysis in experimental statistics and quantitative genetics. Acta Sci Agron. 35(3): 271-276.

Cyril NC, Ayinde DL, Olatunji O (2014) Genetic variability and heritability of vegetative, fruit and seed yield traits in fluted pumpkin (Telfairia occidentalis Hook F.). Afr J Biotechnol.13(32): 3262-3270.

Du X, Sun Y, Li X, Zhou J, Li X (2011) Genetic divergence among inbred lines in Cucurbita moschata from China. Sci Hortic. 127(3): 207-213.

Embrapa - Empresa Brasileira de Pesquisa Agropecuária (2015) Dados meteorológicos da Embrapa Semiárido: Estação Agrometeorológica de Bebedouro. Available online at: http://www.cpatsa.embrapa.

br:8080/servicos/dadosmet/ceb-mes.html (Accessed in 17 October 2016).

Ghasemi A, Zahediasl S (2012) Normality Tests for statistical analysis: a guide for non-statisticians. Int J Endocrinol Metab. 10(2): 486-489.

Hong F, Peng J, Lui W, Chiu H (2014) Investigation on the physicochemical properties of pumpkin flour (Cucurbita moschata) blend with corn by single-screw extruder. J Food Process Preserv. 39(2015): 1342-1354.

IAL - Instituto Adolfo Lutz (1985) Normas analíticas, métodos químicos e físicos para análise de alimentos. 3rd edn. IAL, São Paulo.

Itle RA, Kabelka EA (2009) Correlation between L*a*b* color space values and carotenoid content in pumpkins and squash (Cucurbita spp.). HortScience. 44(3): 633-637.

Janani N, Patel MD, Nihaluddin S.MD, Sharma S (2018) A review of xerophthalmia due to vitamin-A deficiency with ayurvedic management. World J Pharm Res. 8(1): 1685-1691.

Khan ASMMR, Eyasmin R, Rashid MH, Ishtiaque S, Chaki AK (2017) Variability, heritability, character association, path analysis and morphological diversity in snake gourd. Agric and Nat Res. 50(6): 483-489.

Loy JB (2004) Morpho-physiological aspects of productivity and quality in squash and pumpkins (Cucurbita spp.). Crit Rev Plant Sci. 23(4):337-363.

Martínez-Valdivieso D, Gomez P, Font R, Alonso-Moraga A, RíoCelestino M Del (2015) Physical and chemical characterization in fruit from 22 summer squash (Cucurbita pepo L.) cultivars. LWT - Food Sci Technol 64: 1225-1233.

Mezzomo N, Ferreira SRS (2016) Carotenoids functionality, sources, and processing by supercritical technology: a review. J Chem. 2016:1-16.

Miglioli TC, Fonseca VM, Gomes Junior SC, Silva KS da, Lira PIC de, Batista Filho M (2015) Factors associated with the nutritional status of children less than 5 years of age. Rev Saúde Públ. 49: 49-59.

Mustafa M, Syukur M, Sutjahjo SH, Sobir S (2018) Determination of selection criteria for Tomato (Solanum lycopersicum L.) yield component in the lowland based on path analysis. Agrotec J. 3(1): 34-41.

Naik ML, Prasad VM, Raya LP (2015) A study on character association and path analysis in pumpkin (Cucurbita moschato Duch. Ex Poir.). Int J Adv Res. 3(1): 1030-1034.

Ndukauba J, Nwofia GE, Okocha PI, Ene-Obong EE (2015) Variability in Egusi-Melon genotypes (Citrullus lanatus (Thumb) Matsum and Nakai) in derived Savannah environment in South-Eastern Nigeria. Int J Plant Res. 5(1): 1926.

Nerson H, Paris HS, Paris EP (2000) Fruit shape, size and seed yield in Cucurbita pepo. Acta Hort. 510:227-230.

Rodriguez-Amaya, DB, Kimura M (2004) HarvestPlus handbook for carotenoid analysis. HarvestPlus, Washington. Available online at: http://www.harvestplus.org/sites/ default/files/tech02.pdf (Accessed in 20 May 2015).

Saini RK, Nile SH, Park SW (2015) Carotenoids from fruits and vegetables: chemistry, analysis, occurrence, bioavailability and biological activities. Food Res Int. 76: 735-750.

Santos EA dos, Almeida AF de, Branco MC da S, Santos IC dos, Ahnert D, Baligar VC, Valle RR (2018) Path analysis of phenotypic traits in young cacao plants under drought conditions. PLoS One. 13(2): 1-16.

Sasaki FFC, Aguila JS del, Gallo CR, Jacomino AP, Kluge RA (2014) Physiological, qualitative and microbiological changes of minimally processed squash stored at different temperatures. Rev Iber Tecnología Postcosecha. 15(2): 210-220.

Singh PK, Singh VB, Singh CK, Kumar M, Kumar V, Kumar N (2017) Evaluation of germplasm for PCV, GCV and heritability in Luffa (Luffa cylindrica Roem.). Int J Curr Microbiol App Sci. 6 (3): 355-360.

Soltani F, Karimi R, Kashi A (2016) Estimation of genetic diversity in Cucurbita species using morphological and phytochemical analysis. Int J of Veg Sci. 2016(1): 1-12.

Souza TV de (2013) Aspectos estatísticos da análise de trilha. Ufla, Lavras.

Sultana S, Kawochar MA, Naznin SA, Siddik A, Mahmud F (2015) Variability, correlation and path analysis in pumpkin (Cucurbita moschata L.). Bangladesh J Agric Res. 40(3): 479489.

Zhao J, Liu W, Chen D, Song Y, Zhang Y, Ni Y, Li Q (2015) Physicochemical and antioxidant properties of different pumpkin cultivars grown in China. Food Sci Technol. 9(4):308-316.

Zhou C, Liu W, Zhao J, Yuan C, Song Y, Chen D, Ni Y, Li Q (2014) The effect of high hydrostatic pressure on the microbiological quality and physical-chemical characteristics of Pumpkin (Cucurbita maxima Duch.) during refrigerated storage. Innov Food Sci Emerg Technol. 21: 24-34. 